\title{
UM ESTUDO DA IMPLANTAÇÃO DAS BOAS PRÁTICAS DE FABRICAÇÃO EM UMA INDÚSTRIA DE SALGADOS NA CIDADE DE BARBACENA - MG
}

\section{A STUDY OF THE IMPLEMENTATION OF GOOD MANUFACTURING PRACTICES IN A SALTY INDUSTRY IN THE CITY OF BARBACENA - MG}

\author{
Rafael Henrique de Almeida Ferreira' \\ Instituto Federal do Sudeste de Minas Gerais - campus Barbacena; Barbacena, MG - Brasil \\ https://orcid.org/0000-0002-5387-1091 \\ rafaelhenrique93@gmail.com \\ Júlia Fernandes Cunha Reis ${ }^{2}$ \\ Instituto Federal do Sudeste de Minas Gerais - campus Barbacena; Barbacena, MG - Brasil \\ https://orcid.org/0000-0001-9299-1865 \\ jufc.279@gmail.com \\ Doutora Valéria França de Souza ${ }^{3}$ \\ Universidade Federal Rural do Rio de Janeiro; Departamento de Ciência e Tecnologia de \\ Alimentos; Seropédica, RJ - Brasil \\ https://orcid.org/0000-0001-8350-1780 \\ vssouzafrana@gmail.com
}

Profa $^{\text {. Orientadora Doutora Giovana Maria Pereira Assumpção }}{ }^{4}$

Instituto Federal do Sudeste de Minas Gerais - campus Barbacena; Barbacena, MG - Brasil https://orcid.org/0000-0001-7200-5044 giovana.assumpcao@ifsudestemg.edu.br

Prof. Coorientador Henrique Tadeu Resende Silva ${ }^{5}$

Centro Universitário Presidente Tancredo de Almeida Neves; São João del Rei, MG - Brasil https://orcid.org/0000-0001-8051-9619 rickresilva@gmail.com

Profa. Coorientador Doutora Érika Carla da Costa Brumano ${ }^{6}$ Instituto Federal do Sudeste de Minas Gerais - campus Barbacena; Barbacena, MG - Brasil https://orcid.org/0000-0002-0081-2557 erika.brumano@ifsudestemg.edu.br

${ }^{1}$ Concepção, Curadoria de dados, Coleta de dados, Metodologia, Visualização, Redação rascunho original, Redação - revisão e edição e Obtenção de financiamento;

${ }^{2}$ Coleta de dados, Redação - rascunho original e Obtenção de financiamento;

3 Visualização, Redação - revisão e edição e Obtenção de financiamento;

${ }^{4}$ Metodologia, Supervisão, Redação - revisão e edição e Obtenção de financiamento;

5 Metodologia, Supervisão, Redação - revisão e edição e Obtenção de financiamento;

${ }^{6}$ Metodologia, Redação - revisão e edição e Obtenção de financiamento. 


\section{RESUMO}

O presente artigo teve como objetivo verificar as conformidades e não conformidades em uma indústria distribuidora de salgados congelados em Barbacena - MG, de acordo com a Resolução 275/02; bem como, apresentar uma proposta de intervenção no Programa de BPF para a adequação à legislação vigente. Foram realizadas visitas periódicas, entrevistas, avaliação por meio de checklist e avaliações microbiológicas. As análises microbiológicas demonstraram melhorias na higienização da área de produção, dos equipamentos e do ultra congelador. Os equipamentos de refrigeração apresentaram altas contagens de unidades formadoras de colônias. Os requisitos imediatos do plano de ação conseguiram ser adaptados para atingir as conformidades. Com as adaptações realizadas a empresa passou a ser classificada como grupo 1 (RDC 275/2002). Mas ainda existem melhorias a serem implementadas necessitando de um profissional qualificado.

Palavras-chave: Segurança dos Alimentos. Controle de Qualidade. Checklist.

\section{ABSTRACT}

The present article aims to verify the conformity and nonconformity, according with the Resolution 275/02, in a frozen-salty distribution industry located in the City of Barbacena (State of Minas Gerais), as well as to present a intervention proposal in the GMP for the adequacy with the current legislation. Periodic visits, interviews, evaluation through a checklist, and microbiological evaluations were carried out for this research.An action plan was also designed; which included improvements throughout the company. To check the effectiveness of the implementation, the checklist was reapplied and the microbiological analyzes were revalidated. The GMP and SOPs have been updated. Microbiological analysis showed improvements in the production area hygiene, equipment, and ultra-freezer. The refrigeration equipment showed a high count in the colony forming units. The immediate requirements of the action plan were able to be adapted to reach conformity. With the adaptations implemented, the company changed its classification to group 1 (Resolution 275/2002). However, there are still improvements to be implemented, which requires a qualified professional.

Keywords: Food Safety. Quality control. Checklist.

\section{INTRODUÇÃO}

A qualidade na preparação de alimentos deixou de ser uma vantagem competitiva e se tornou requisito fundamental para sua comercialização, devendo atender principalmente os parâmetros microbiológicos, que colaboram para redução dos surtos das doenças transmitidas por alimentos (DTAs) (ANDRÉ, 2017; MACHADO, 2012).

Em sua maioria, DTAs são toxinfecções causadas por bactérias, toxinas bacterianas, vírus e parasitas carreados por alimentos e/ou água, e são conhecidas mais de 250 tipos, sendo que o surto é classificado quando duas ou mais pessoas apresentam sintomas semelhantes após ingestão da fonte alimentícia de mesma origem (BRASIL, 2017).

A taxa de letalidade dos surtos de DTAs no Brasil aumentou de 0,04 \% em 2000 para 0,13\% em 2018, segundo histórico do Sistema de Informação de Agravos de Notificação (SINAN), do Ministério da Saúde (BRASIL, 2018; BRASIL, 2019). Associado a este fato, estão as mudanças nos hábitos alimentares da população brasileira, cuja 
dieta que era baseada em grãos, tubérculos, frutas, legumes, feijão e arroz, foi substituída pelo consumo crescente de produtos industrializados e refeições fora do domicílio, como os fast-foods (CAIN; SANTOS; NOVELLO, 2016).

Alimentos mistos lideram o ranking de alimentos envolvidos com surtos de DTAs $(25,5 \%)$ segundo dados divulgados em estudo do perfil epidemiológico do Ministério da Saúde (BRASIL, 2019). Dessa forma, fazse necessário a avaliação e a implementação de programas de qualidade nesse setor, sendo as Boas Práticas de Fabricação (BPFs) juntamente com os Procedimentos Operacionais Padronizados (POPs), os primeiros passos a serem seguidos para a busca da qualidade na indústria alimentícia.

Este estudo teve como objetivo verificar as conformidades e não conformidades em uma indústria produtora de salgados congelados em Barbacena - MG, de acordo com a Resolução 275/02 (BRASIL, 2002) e apresentar, caso necessário, uma proposta de intervenção no Programa de BPF para a adequação à legislação vigente.

\section{METODOLOGIA}

\subsection{Caracterização da Empresa}

A empresa, objeto deste estudo, situase na cidade de Barbacena-MG. É uma empresa de médio porte com produção diária de 25 mil salgados de diversos tamanhos, atendendo a buffets, supermercados, padarias, lanchonetes e lojas de conveniências de Barbacena e região. Sua produção compreende os seguintes produtos: esfirra, "joelho de moça", cachorro quente, hambúrguer assado, tortinhas, coxinhas, quibes, cigarretes, risoles, bolinhas, travesseirinho, pastéis, empadas, enroladinho de salsicha e churros doces.

\subsection{Aplicação da lista de verificação}

Para realização do diagnóstico inicial das Boas Práticas de Fabricação adotadas na empresa, foram realizadas visitas semanais, in loco, entre os meses de julho a setembro de 2018 com a aplicação da lista de verificação (checklist) disponível na RDC $\mathrm{n}^{\circ} 275$ (BRASIL, 2002). Foram avaliadas as condições das edificações e instalações, equipamentos, móveis e utensílios, produção e transporte de alimentos, rotulagem e armazenamento do produto final, por meio de observação visual.

Para o preenchimento do checklist, três opções de resposta foram utilizadas: C (conforme) quando o item verificado se encontrava dentro da conformidade; NC (não conforme) quando o item verificado não atendia a legislação; e NA (não aplicável) quando o item observado não era aplicável ao estabelecimento.

\subsection{Análises Microbiológicas}

Avaliou-se por meio de técnicas microbiológicas as superfícies que entram em 
contato com os alimentos, a qualidade do ar do ambiente de processamento e a qualidade da água.

\subsubsection{Equipamentos}

As amostras das superfícies em contato com os alimentos foram coletadas $e$ imediatamente enviadas ao Laboratório de Microbiologia de Alimentos do Instituto Federal do Sudeste de Minas - Campus Barbacena em transporte terceirizado na temperatura ambiente para realização das análises. A coleta foi realizada com as peças e equipamentos prontos para o uso de acordo com os padrões da empresa, sendo utilizada a técnica do swab (ANDRADE, 2008), seguido de plaqueamento em Ágar Baird Parker e incubação à $35^{\circ} \mathrm{C}$ por 48 horas, para Staphylococcus spp. e determinação de presença/ausência de coliformes totais e termotolerante em caldo LST e EC (SILVA, 2010).

\subsubsection{Ambiente de processamento}

As amostras da qualidade do ar do ambiente de processamento foram coletadas e imediatamente transportadas até o Laboratório de Microbiologia de Alimentos do Instituto Federal do Sudeste de Minas Campus Barbacena em transporte terceirizado na temperatura ambiente para realização das análises. As amostras foram coletadas no momento da realização do diagnóstico inicial e após a implementação das ações visando à adequação das não conformidades, para avaliação da eficiência das mesmas. Foi avaliada a qualidade do ar do ambiente de processamento, que era dividido em dois ambientes por uma barreira física (Ambientes 1 e 2), por meio da técnica da sedimentação simples em meio de cultura solidificado Ágar para contagem total (PCA) (ANDRADE, 2008). Também foi avaliada a qualidade do ar com o uso do ventilador que era utilizado para resfriamento de recheios e o interior dos equipamentos de conservação de alimentos: ultra congelador, câmara de congelamento e geladeira.

\subsubsection{Avaliação da qualidade} microbiológica de água utilizada na indústria

Para a coleta da água proveniente de poço artesiano foram utilizados frascos de polietileno de $500 \mathrm{~mL}$ que foram desinfetados de acordo com a normativa do Manual Prático de Análise da Água (FUNASA, 2003). As amostras coletadas foram devidamente acondicionadas em caixas de isopor, conservadas em gelo e transportadas até o Laboratório de Controle de Qualidade de Água, Alimentos, Bebidas e Efluentes de Juiz de Fora para a contagem padrão, coliformes a 35으 e Escherichia coli segundo método descrito na Instrução Normativa nำ62, de 26 de agosto de 2003 (BRASIL, 2003).

\subsection{Plano de Ação}


Após a aplicação da lista de verificação, foi elaborado, junto ao proprietário, um plano de ação imediato.

\subsection{Atividades de Verificação}

Para a verificação da efetividade das mudanças propostas no plano de ação, foi reaplicada a lista de verificação da $\mathrm{RDC}$ 275/02 (BRASIL, 2002) e obtido um comparativo da porcentagem das adequações à resolução. Foram avaliadas também as condições microbiológicas do moedor de carne, máquina de salgados e a qualidade do ar do ambiente de processamento seguindo metodologia descrita no item 2.3.

\subsection{Atualização do Manual de Boas} Práticas de Fabricação

Inicialmente foi proposto um Plano de Ação para realização de adequações baseado no diagnóstico obtido por meio do

Figura 1 - Resultado da aplicação da lista de verificação antes e após implantação das BPF. checklist. O mesmo foi revisado e anexado ao Manual de Boas Práticas para a empresa acompanhar as mudanças futuras. Foi atualizado o Manual de BPF em conjunto com os proprietários da empresa.

\section{RESULTADOS E DISCUSSÃO}

\subsection{Aplicação do checklist de diagnóstico inicial e final}

Após a primeira aplicação do checklist e proposto o plano de ação, a indústria realizou as ações que estavam ao seu alcance para adequar às exigências e atender às conformidades.

O checklist foi reaplicado para avaliação realizando um comparativo dos dois momentos de avaliação (Figura 1) 


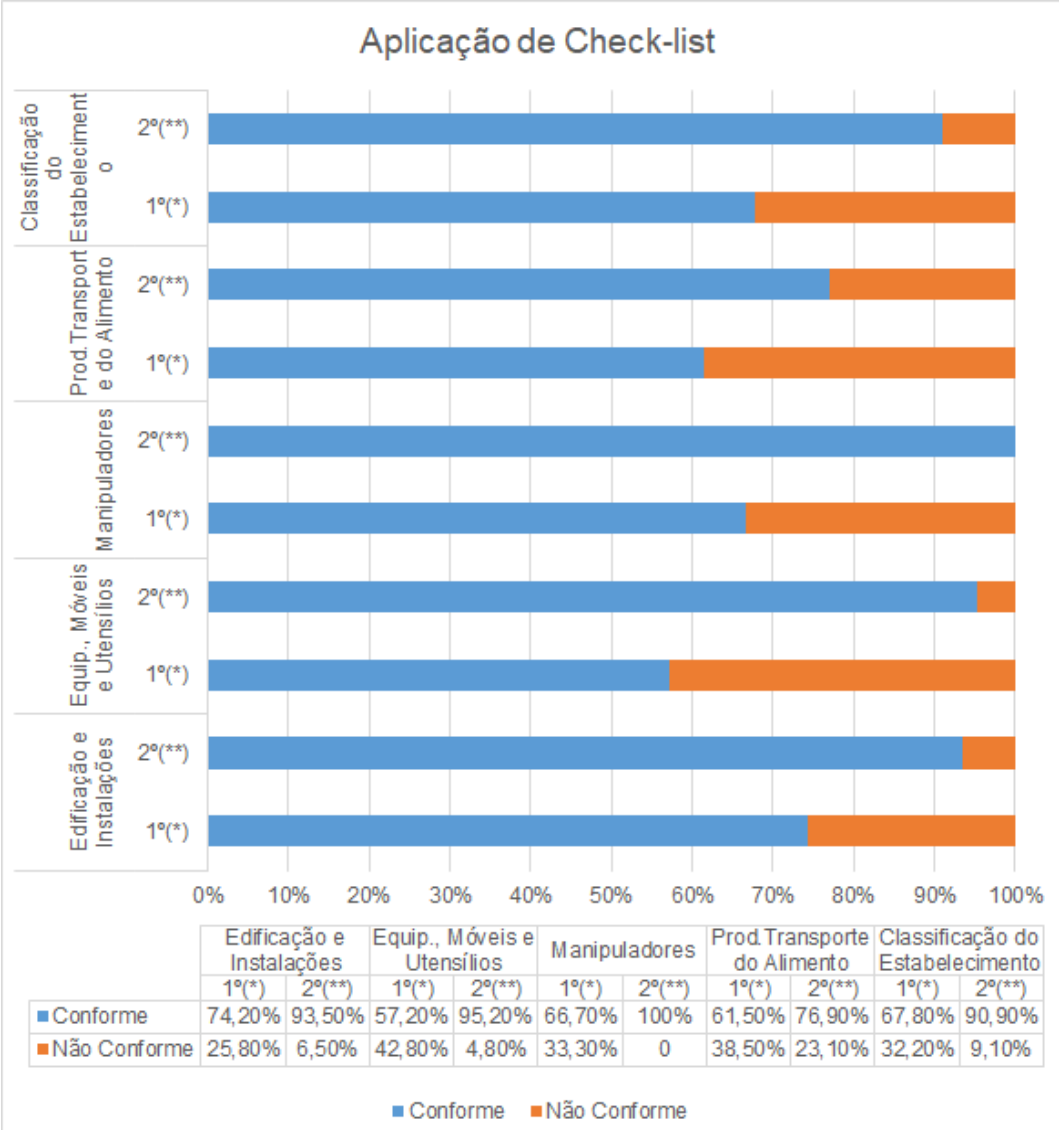

$\left.{ }^{*}\right) 1^{\circ}$ - Primeira aplicação da lista de verificação; $\left({ }^{* *}\right) 2^{\circ}$ - Segunda aplicação da lista de verificação; Fonte: Rafael H. de Almeida Ferreira e Júlia F. Cunha Reis, 2018.

O item Edificações e Instalações que apresentava $74,2 \%$ de conformidades antes da implementação, passou a atender 93,5 \% com as ações do programa de qualidade, nos seguintes quesitos:

- Revestimento de instalações elétricas;

- Designação de colaborador para tarefas de higienização;

- Alteração do layout da empresa para evitar contaminação cruzada;

- Substituição do acesso da empresa que era comum com de habitações;

- Aquisição de sabonete líquido, inodoro e antisséptico para banheiros e área de manipulação;
- Aquisição de produtos de higienização específicos para a atividade da empresa e regularizados pelo Ministério da Saúde, estando sempre disponíveis na empresa e usado da forma indicada pelo fabricante, atingindo assim uma higienização adequada.

Baseando-se nas justificativas acima, Belphman (2017) relata que o layout e as áreas de processamento e manipulação, devem seguir um fluxo ininterrupto e higienicamente adequado, a fim de minimizar riscos de contaminação cruzada. 
Segundo a RDC 216/2004 (BRASIL, 2004), as instalações e as edificações devem contribuir para um fluxo ordenado e sem cruzamentos em todas as áreas de processamento e manipulação, contribuindo para a seguridade microbiológica dos alimentos.

No item Equipamentos, Móveis e Utensílios houve um aumento de $38 \%$ de conformidades de uma avaliação para a outra, atendendo os seguintes quesitos:

- Designação de colaborador treinado para execução de tarefas de higienização;

- Implantação de planilhas para o registro do controle de temperaturas de equipamentos de conservação de alimentos (refrigeradores, congeladores e câmara frigorífica);

- Aquisição de produtos de higienização específicos para as atividades da empresa e regularizados pelo Ministério da Saúde, estando sempre disponível na empresa e usado da forma indicada pelo fabricante, atingindo assim uma higienização adequada.

Tendo em vista os quesitos mencionados, durante a manipulação dos alimentos, objetiva-se adequados procedimentos referentes a higienização de utensílios e equipamentos, matéria prima, manipuladores, além das etapas de recepção, armazenagem, preparo e distribuição para o consumidor final, de modo a garantir a segurança do alimento, e as características sensoriais e nutricionais (MAGNONI et al., 2016).

No item Manipuladores atingiu-se 100 $\%$ de conformidades, em contrapartida aos $66,7 \%$ atendidos na primeira avaliação. A fixação de cartazes de orientações em geral aos manipuladores e a realização de atividades de capacitação foram as ações responsáveis para o cumprimento deste item.

Assim como o item que se refere a manipuladores, para Rodrigues et al., (2017) uma das principais formas de contaminação dos alimentos são os manipuladores, que assim como os utensílios e equipamentos mal higienizados, podem aumentar em até $26 \%$ as causas de contaminação conforme a Organização Pan-americana da Saúde (OPAS).

Quanto ao item Produção e Transporte do Alimento houve variação positiva nas conformidades de $15,4 \%$, sendo o item com menor desempenho. Observaramse melhorias quanto ao acondicionamento de embalagens, controle da circulação e acesso do pessoal. Também houve melhorias no fluxo de produção e implantação de planilhas para o registro do controle de temperaturas de equipamentos de refrigeração.

Segundo a resolução RDC no216/2004, as matérias primas, os ingredientes e as embalagens devem ser armazenados em local limpo e organizado, de forma a garantir proteção contra os 
contaminantes. Devem estar adequadamente acondicionados e identificados, sendo que sua utilização deve respeitar o prazo de validade (BRASIL, 2004).

O próximo passo será a aquisição de veículo adequado para o transporte de perecíveis que não foi possível por necessitar de planejamento financeiro prévio para tal investimento. De acordo com as recomendações da legislação, para transporte de alimentos o veículo deve preencher requisitos básicos para garantir sua qualidade, sendo esses: ter a cabine do condutor isolada da parte que contém os alimentos; possuir certificado de vistoria, de acordo com a legislação vigente; usar materiais para proteção e fixação de carga que não constituam fonte de contaminação ou dano para o alimento; estar equipado com estrados e caixas plásticas para 0 acondicionamento dos alimentos; ser mantido em ótimas condições de limpeza; e ser mantido sob refrigeração no caso dos alimentos frios e perecíveis (BRASIL, 2002).
De acordo com a classificação disponível na RDC 275/02 (BRASIL, 2002), no panorama geral, a empresa encontrava-se classificada no Grupo 2 atendendo entre 51 a $75 \%$ das conformidades. E como resultado das ações implantadas a empresa passou a ser classificada no grupo 1 atendendo entre $76 \%$ a $100 \%$ dos itens avaliados na lista de verificação das BPF em estabelecimentos produtores/industrializadores de alimentos.

Baseando-se nos resultados obtidos, com a avaliação das Boas Práticas na indústria de salgados, pode-se observar um ótimo resultado em conformidade na classificação geral.

\subsection{Melhorias propostas no Plano de Ação}

Foi apresentado o plano de ação logo após a aplicação do primeiro checklist, com a implantação de medidas pela empresa durante a execução do projeto (Quadros 1 e 2). Algumas sugestões foram atendidas, entretanto outras, exigem maior tempo para implementação.

Quadro 1 - Medidas implantadas pela indústria de salgados durante o tempo de execução do projeto, entre Julho e Novembro de 2018.

\section{Melhorias Implantadas}

Fixação de procedimentos visuais para higiene de mãos na pia exclusivas para este fim.

Fixação de avisos educativos e placas de lixo, de proibido fumar, de entrada exclusiva para funcionários, de entrada permitida apenas com uso de uniforme e touca e para manter portas fechadas.

Aquisição de sabonete líquido, inodoro e antisséptico para banheiros e área de manipulação. 
Regularização do uso de produtos de higienização, trocando o sabão em barra caseiro por detergentes neutros ou alcalinos específicos para a atividade da empresa e autorizados pelo Ministério da Saúde.

Treinamento de diluições e concentrações do Hipoclorito de Sódio para sanitização.

Designação de colaboradores para tarefas de higienização.

Substituição do acesso da empresa que era comum com de habitações; Controle da circulação e acesso do pessoal.

Revestimento de instalações elétricas e adaptação da fiação para que não atravesse o caminho dos manipuladores.

Alteração do leiaute da empresa para evitar contaminação cruzada, apresentando melhorias no fluxo de produção.

Implantação de planilhas para o registro do controle de temperaturas de equipamentos de conservação de alimentos (refrigeradores, congeladores e câmara frigorífica).

Melhorias quanto ao acondicionamento de embalagens.

Alteração no método de resfriamento dos recheios. Era realizado por ventilação com ventilador comum por uso da imersão parcial dos recipientes contendo recheio em água fria e gelo.

Fonte: Rafael H. de Almeida Ferreira e Júlia F. Cunha Reis, 2018.

Quadro 2 - Medidas sugeridas à indústria de salgados para serem implantadas a longo prazo. Melhorias Sugeridas

Implantação de cronograma para higienização (Chão, ralos, geladeira, câmara fria....). Incluindo procedimento, frequência, produtos utilizados em cada operação e tempo de contato dos desinfetantes utilizados. Além do cronograma, precisa-se melhorar a descrição das diluições de produtos de higienização.

Adoção de formulário para controle das operações de higienização de equipamentos e instalações que não são realizadas diariamente.

Controle da qualidade de higiene das mãos dos manipuladores através de análise microbiológica por empresa terceirizada.

Controle da qualidade de higiene das superfícies que entram em contato direto com a alimento através de análise microbiológica por empresa terceirizada.

Controle da qualidade dos produtos produzidos na empresa através de análise microbiológica por empresa terceirizada.

Coleta e armazenamento de amostras de lotes produzidos na empresa, acompanhado de registro; controle da Vida de Prateleira dos produtos com periodicidade.

Obtenção e instalação de pia com acionamento automático.

Obtenção e instalação de sistema de fechamento automático das portas que dão acesso a área de manipulação. 
Reforma dos rodapés, tornando-os arredondados.

Troca das telas que estão rasgadas e adaptação de telas que se encontram com frestas.

Aquisição de carro específico e exclusivo para transporte dos produtos acabados com sistema de refrigeração.

Registro de calibração e manutenção de balanças e termômetros.

Aquisição e instalação de porta ou cortina de plástico para acesso a escada que leva ao estoque e segundo andar da fábrica.

Aquisição de cortina de vento para minimizar perda de frio quando realizar abertura da câmara fria (apenas sugestão para economia de energia).

Treinamento para higienização de geladeira e câmara fria

Fonte: Rafael H. de Almeida Ferreira e Júlia F. Cunha Reis, 2018

Houve disponibilidade, participação e envolvimento da equipe de colaboradores e dos proprietários nas etapas de implantação do programa, o que foi se suma importância para a realização do trabalho. A orientação de um profissional capacitado em controle de qualidade foi indispensável para adequação das normas exigidas pela legislação, sendo esse capaz de discernir quais medidas devem ser adotadas a curto, médio e longo prazo. É fundamental que a empresa dê continuidade ao controle da qualidade sob a orientação do técnico, visando 0 atendimento das exigências da RDC 275/02 (BRASIL, 2002).

\subsection{Avaliação Microbiológica do ambiente da indústria}

A Tabela 1 apresenta os resultados da avaliação microbiológica do ar de ambientes/equipamentos da indústria antes e após a implementação do plano de ação.

Tabela 1 - Resultados da avaliação da qualidade microbiológica do ar dos ambientes e interiores de equipamento de refrigeração e congelamento, em UFC.cm ${ }^{-2}$.semana ${ }^{-1}$

\begin{tabular}{|c|c|c|}
\hline Ambiente & $\begin{array}{c}\text { UFC. } \mathrm{cm}^{-2} \text {.semana }{ }^{-1} \\
\text { Antes }\end{array}$ & $\begin{array}{c}\text { UFC. } \mathrm{cm}^{-2} \text {.semana }{ }^{-1} \\
\text { Depois }\end{array}$ \\
\hline Área de manipulação $1\left(^{*}\right)$ & 316 & 213 \\
\hline Área de manipulação 1 com uso do ventilador & 374 & - \\
\hline Área de manipulação $2\left(^{* \star}\right)$ & 217 & 98 \\
\hline Câmara de congelamento & 41 & 913 \\
\hline Ultra congelador & 36 & 20 \\
\hline Geladeira & 222 & 261 \\
\hline
\end{tabular}

(*) Área de elaboração de recheios, massas, fritura e higienização de equipamentos e utensílios.

${ }^{* *}$ Área de produção, congelamento e embalagens dos salgados e armazenamento de recheios prontos. 
Fonte: Rafael H. de Almeida Ferreira e Júlia F. Cunha Reis, 2018.

Após a aquisição e o uso de materiais de higienização adequados à atividade nas áreas de manipulação 1 e 2 houve uma redução na contagem das unidades formadoras de colônias (redução de 103 e 119 UFC. $\mathrm{cm}^{-2}$.semana ${ }^{-1}$, respectivamente). Por requerer um tempo maior dentro da empresa, não foi estabelecido um programa de higienização dos equipamentos (geladeira e câmara de congelamento) o que pode ter contribuído para o aumento da contagem de colônias, podendo revelar a importância da implementação do programa.

O uso do ventilador como método adotado de resfriamento dos recheios contribuiu para o aumento considerável da contagem de unidades formadoras de colônia, de 316 para 374 UFC. $\mathrm{cm}^{-2}$. semana-1 o que pode contribuir para diminuir a qualidade do ar da área avaliada, comprometendo as atividades realizadas.

De acordo com a Tabela 1, na avaliação de ambiente não refrigerado, constatou-se que a área de manipulação 1 encontra-se com contagens maiores antes do treinamento e contagens menores depois do treinamento para mesófilos aeróbios.

Nos ambientes refrigerados também encontraram-se contagens maiores para mesófilos aeróbios nas áreas de manipulação 1 com uso do ventilador, área de manipulação 2 e geladeira conforme Tabela 1.
Entre os ambientes refrigerados estão incluídas câmara de congelamento e ultra congelador que estão abaixo do limite estabelecido para mesófilos aeróbios conforme Tabela 1. No entanto, na avaliação microbiológica após o treinamento a contagem de UFC do ar do interior da câmara de congelamento apresentou um resultado consideravelmente superior. Verificou-se no dia da coleta que juntamente com os salgados pronto para comercialização estava estocado salgados crus em bandejas, salgados assados sem embalagem e carne crua congelada o que pode ter contribuído com esse aumento da contagem.

Constatou-se, em relação aos mesófilos aeróbios, que todos os ambientes avaliados na Tabela 1 encontram-se em qualidade insatisfatória.

Compararam-se os valores deste estudo com a recomendação de Andrade (2008), que limita o número de 80 UFC.cm ${ }^{2}$. semana $^{-1}$ em ambientes refrigerados $e$ ambientes não refrigerados de 250 UFC.cm ${ }^{2}$.semana ${ }^{-1}$ para mesófilos aeróbios presentes no ar de ambientes na área de processamento de alimentos, em condições higiênicas adequadas.

\subsection{Análises microbiológicas dos equipamentos}

As tabelas 3 e 4 apresentam os resultados antes e depois do treinamento, da 
eficiência da higienização dos equipamentos envolvidos na produção dos salgados, pela determinação de presença/ausência de coliformes totais e termotolerantes e a contagem de UFC de Staphylococcus aureus pelo meio de cultura Baird Parker (BP).

Tabela 2 - Resultado das contagens de Staphylococcus aureus realizadas nos equipamentos da indústria de salgados de Barbacena - MG.

\begin{tabular}{ccc}
\hline Equipamentos & $\begin{array}{c}\text { UFC.cm-2 } \\
\text { antes }\end{array}$ & $\begin{array}{c}\text { UFC.cm } \\
\text { depois }\end{array}$ \\
\hline $\begin{array}{c}\text { Rosca sem fim } \\
\text { do Moedor }\end{array}$ & $4,6 \times 10^{2}$ & 0 \\
$\begin{array}{c}\text { Esteira da } \\
\text { Masseira }\end{array}$ & 0 & 0 \\
$\begin{array}{c}\text { Cuba 1 da } \\
\text { Masseira }\end{array}$ & $2,3 \times 10^{3}$ & 0 \\
$\begin{array}{c}\text { Cuba 2 da } \\
\text { Masseira }\end{array}$ & $1,3 \times 10^{3}$ & 0 \\
\hline
\end{tabular}

Fonte: Rafael H. de Almeida Ferreira e Júlia F. Cunha Reis, 2018.

Com os resultados do presente estudo para os equipamentos (rosca sem fim do moedor, cuba 1 e 2 da masseira) antes do treinamento, nota-se que os valores encontrados, em UFC. $\mathrm{cm}^{-2}$, foram superiores comparados ao citado por APHA (1992). Segundo a American Public Health Association (APHA,1992), o valor recomendado é de 2 UFC. $\mathrm{cm}^{-2}$ de área de equipamento, para que uma superfície seja considerada higienizada.

Desta forma, pode-se observar que a esteira da masseira encontrava-se de acordo com o recomendado antes e depois, com valores de UFC. $\mathrm{cm}^{-2}$ abaixo do recomendado pela APHA (1992) conforme Tabela 2.

Deve ser levado em consideração o processamento aplicado de higienização e os produtos de limpeza resultando em valores superiores (UFC. $\mathrm{cm}^{-2}$ ) antes do treinamento para os equipamentos (rosca sem fim do moedor, cuba 1 e 2 da masseira). Após o treinamento, as superfícies de todos os equipamentos analisados apresentaram contagens de Staphylococcus aureus abaixo do valor recomendado pela APHA.

Tabela 3 - Resultado da avaliação de ausência/presença de Coliformes totais (Caldo LST) e termotolerantes (Caldo EC) em equipamentos de indústria de salgados de Barbacena - MG.

\begin{tabular}{c|cl|ll}
\hline \multirow{2}{*}{ Equipamento } & \multicolumn{2}{|c|}{ Coliformes totais } & \multicolumn{2}{c}{ Coliformes termotolerantes } \\
\cline { 2 - 5 } & Antes & Depois & Antes & Depois \\
\hline Rosca sem fim do Moedor & presente & ausente & ausente & - \\
Esteira da Masseira & presente & ausente & ausente & - \\
Cuba 1 da Masseira & presente & ausente & ausente & - \\
Cuba 2 da Masseira & presente & ausente & ausente & - \\
\hline
\end{tabular}


Fonte: Rafael H. de Almeida Ferreira e Júlia F. Cunha Reis, 2018.

A adequação das etapas de higienização adotadas pela empresa garantiu a melhoria da condição microbiológica, em relação à ausência de coliformes totais. Estes resultados podem estar relacionados ao treinamento e ao uso de produtos adequados para a atividade, como detergentes neutros, detergentes alcalinos e hipoclorito de sódio, bem como ao emprego correto das diluições dos mesmos. Na Tabela 3 os equipamentos mostraram resultados isentos de contaminação para os Coliformes termotolerantes.

\subsection{Análises microbiológicas da água}

A qualidade da água na área de produção é de suma importância por ser usada como ingrediente em preparos de produtos, na higienização de superfícies, utensílios e equipamentos, consumo pelos funcionários e na diluição dos detergentes e sanitizantes. Soma-se a isso que parte da água utilizada pela empresa é captada de poço artesiano e misturada na caixa de armazenamento da indústria com água fornecida pela Companhia de Saneamento de Minas Gerais (Copasa). A tabela 4 apresenta os resultados das análises microbiológicas da água captada diretamente do poço artesiano que se encontra na indústria.

Tabela 4 - Resultado das análises microbiológicas da água captada em poço artesiano utilizada em uma indústria de salgados de Barbacena - MG.

Revista Higiene Alimentar, 35 (293): e1069, 2021

ISSN 2675-0260 - DOI: 10.37585/HA2021.02implantacao

\begin{tabular}{cc}
\hline Parâmetros & Resultados \\
\hline Contagem Padrão & $>1,5 \times 10^{-5} \mathrm{UFC} / \mathrm{mL}$ \\
Coliformes Totais à & ausência em $100 \mathrm{~mL}$ \\
$35^{\circ} \mathrm{C}$ & \\
E.coli & ausência em $100 \mathrm{~mL}$ \\
\hline
\end{tabular}

Fonte: Dados coletados por empresa terceirizada, 2018.

Nas indústrias utiliza-se a água em grande quantidade, 0 que influencia diretamente na qualidade do produto final, sendo assim a mesma deve apresentar padrões microbiológicos adequados. $\mathrm{A}$ avaliação de coliformes à $35^{\circ} \mathrm{C}$ e de E.coli estão dentro dos padrões da Resolução CONAMA, $n=396$, de 3 de abril de 2008 e para a contagem padrão não há limite definido (BRASIL, 2008).

Dados semelhantes também são relatados em estudo realizado por Santana (2019), no qual expôs os resultados das amostras dos poços em conformidade com o padrão microbiológico que deve apresentar ausência de bactérias do grupo coliformes totais e Escherichia coli, em $100 \mathrm{ml}$ de água. Por outro lado, Alves, Ataíde e Silva (2018) verificaram que das cinco amostras em água de bebedouros realizadas no Parque Ecológico de Águas Claras - Distrito Federal, obtiveram resultados negativos para coliformes totais e termotolerantes.

Resultados superiores de contaminação de água subterrânea de poços 
artesianos por Coliformes Totais e E.coli foram observados por Zamilian, Paula e Zamilian (2018) em seu artigo Avaliação microbiológica de águas de poços artesianos em propriedades rurais no município de colorado do oeste - Rondônia. Onde relataram apenas três amostras (poços no 2, 7 e 10) mostraram-se positivas, tanto para Coliformes Totais quanto para Coliformes Termotolerantes (Escherichia coli).

\subsection{Entrega da Revisão do Manual de BPF}

A entrega do manual revisado ocorreu em dezembro de 2018, contendo como previsto o Plano de Ação e os POPs. O tempo de execução foi curto exigindo um grande empenho de todos os envolvidos. Marchiori (2015) em seu trabalho intitulado de "Diagnóstico e implantação de boas práticas de fabricação em uma indústria de conservas do município de Francisco Beltrão - PR", iniciou o diagnóstico da empresa em setembro de 2014 e iniciou a elaboração do manual após 12 meses de acompanhamento na empresa citada, sendo um tempo superior ao disponível comparado à elaboração deste projeto.

\section{CONCLUSÕES}

De acordo com o critério de classificação estabelecido na legislação vigente, RDC 275/2002, a indústria de salgado foi classificada no grupo 1, com respectivamente, entre 76 a $100 \%$ de adequação na lista de verificação das Boas Práticas de Fabricação.

Foi possível realizar o diagnóstico da empresa com a metodologia adotada e propor adequações para atender à legislação.

Foi viável implementar melhorias quanto a edificações e instalações; produção e transporte do alimento; e na documentação exigida.

A implantação das BPFs é um processo dinâmico e deve estar sempre em avaliação e revisão para garantir a efetividade.

\section{REFERÊNCIAS BIBLIOGRÁFICAS}

ALVES, S. G. S.; ATAIDE, C. D. G.; SILVA, J. X. Análise microbiológica de coliformes totais e termotolerantes em água de bebedouros de um parque público de Brasília, Distrito Federal, Revista de Divulgação Científica Sena Aires, v.7, n.1, p.12-17, 2018.

ANDRADE, N. J. Higiene na Indústria de alimentos: avaliação e controle de adesão e formação de biofilme bacteriano. 412p. : il. São Paulo: Varela, 2008.

ANDRÉ, M. V. Controle da Qualidade em Microbiologia Alimentar - Estágio em laboratório com acreditação IPAC segundo a NP EN ISO/IEC 17025. 2017. 61p. Dissertação (Mestrado em Gestão da Qualidade e Segurança Alimentar) - Escola Superior de Tecnologia e Gestão do Instituto Politécnico de Viana do Castelo. Viana do Castelo. Acesso em: 06 de Agosto de 2018. Disponível em:

$<$ http://repositorio.ipvc.pt/bitstream/ 20.500.11960/1951/1/Menalda_Andre.pdf> Examination of Dairy Products. 16th. ed.: 
Richardson, G. H. American Public Health Association, Washington, D.C. 1992.

BELPHMAN, C. Readequação do layout de uma unidade de alimentação e nutrição hospitalar da cidade de Ponta Grossa Paraná, Revista Nutrir, v.1, n.5, 2017.

BRASIL. Ministério da Saúde. Secretaria de Vigilância em Saúde. Departamento de Vigilância das Doenças Transmissíveis. Coordenação Geral de Doenças Transmissíveis. Surtos de Doenças transmitidas por alimentos no Brasil: Informe 2018. 2019. Disponível em: <https://portalarquivos2.saude.gov.br/images/ pdf/2019/fevereiro/15/ Apresenta----o-SurtosDTA---Fevereiro-2019.pdf> Acesso em: 02 de dezembro de 2020

BRASIL. Ministério da Saúde. Secretaria de Vigilância em Saúde. Departamento de Vigilância das Doenças Transmissíveis. Coordenação Geral de Doenças Transmissíveis. Surtos de Doenças transmitidas por alimentos no Brasil. 2018. Disponível em:

$<$ https://portalarquivos2.saude.gov.br/images/ pdf/2018/janeiro/17/Apresentacao-SurtosDTA-2018.pdf> Acesso em: 02 de dezembro de 2020

BRASIL. Ministério da Agricultura, Pecuária e Abastecimento. Secretaria de Defesa Agropecuária. Instrução Normativa nํ6ㅇ de 26 de Agosto de 2003. Métodos Analíticos Oficiais para Análises Microbiológicas para Controle de Produtos de Origem Animal e Água. Diário Oficial da União, Brasília, 2003.

BRASIL. Agência Nacional de Vigilância Sanitária. Resolução RDC no 216, de 14 de setembro de 2004. Regulamento Técnico de Boas Práticas para Serviços de Alimentação. Diário Oficial da União, Brasília, DF, 2004.

BRASIL. Ministério da Saúde. Agência Nacional de Vigilância Sanitária. Resolução RDC no 275, de 21 de outubro de 2002. Regulamento técnico de procedimentos operacionais padronizados aplicados aos estabelecimentos produtores/industrializadores de alimentos e a lista de verificação das boas práticas de fabricação em estabelecimentos produtores/ industrializadores de alimentos.Diário Oficial da União, Brasília, 2002.

CAIN, J. P.; SANTOS, E. F.; NOVELLO, D. Avaliação dos teores nutricionais de produtos comercializados em redes de fast foods no Brasil. Multitemas, Campo Grande, v.21, n.50, p.9-30, 2016.

CARÚS, J. P.; FRANÇA, G. V. A.; BARROS, A. J. D. Local e tipo das refeições realizadas por adultos em cidades de médio porte.

Revista de Saúde Pública, Pelotas, v.48, n.1, p.68-74, 2014.

\section{FUNASA. Manual prático de análise de} água. Brasília, 2003.

MACHADO, S. S. Gestão da Qualidade. 92 p. : il. Inhumas: IFG; Santa Maria:

Universidade Federal de Santa Maria, 2012.

MAGNONI, D.; TARDIOLI, M.; ZAGATO, M.; MIYAGI, M.; TAKAYAMA, P.; MOURA, S.; KOVACS, C.; CAMELO, V.; BARBOSA, M.; CUKIER, C. Segurança alimentar e informação nutricional podem reduzir a intoxicação alimentar na alimentação fora do lar. Revista Brasileira de Nutrição Clínica, São Paulo, v.31, n.2, p.91-96, 2016.

MARCHIORI, C. Diagnóstico e implantação de Boas Práticas de Fabricação em uma indústria de conservas do município de Francisco Beltrão - PR. 2015. 65p. Monografia (Especialização em Gestão da Qualidade na Tecnologia de Alimentos) Universidade Tecnológica Federal do Paraná - UTFPR. Francisco Beltrão - PR.

RODRIGUES, A.A.; SOUSA, W.L.; PINHEIRO, R.E.E.; CARVALHO, A.P.L.S. Aspectos higiênico-sanitários de estabelecimentos comercializadores de carnes no município de Bom Jesus - PI, 
Revista Brasileira de Higiene e Sanidade

Animal, v.11, n.1, p.94-103, 2017.

SANTANA, J. C. Avaliação da qualidade microbiológica da água de poços artesianos em quatro bairros do município de Tabatinga-AM. 2019. 50p.

Monografia (Graduação em Ciências Biológicas)- Universidade do Estado do Amazonas- UEA. Tabatinga-AM.

SILVA, N. et al. Manual de Métodos de Análise Microbiológica de Alimentos e Água. Livraria Varela. 4 ed. 2010.

ZAMILIAN, A. A. E.; PAULA, G. P.; ZAMILIAN, J. A. E. Avaliação microbiológica de águas de poços artesianos em propriedades rurais no município de Colorado do Oeste - Rondônia. Revista

Saúde e Desenvolvimento Humano, v.6, n.3, p.25-37, 2018. 